\title{
COMMISSIONING OF THE 100 KEV BEAM STAGE OF THE INJECTOR LINAC OF THE IFUSP MICROTRON
}

\author{
T. F. Silva*, A. A. Malafronte, A. L. Bonini, R. R. Lima, M. N. Martins \\ Laboratório do Acelerador Linear, Instituto de Física da Universidade de São Paulo. \\ PO Box 66318, 05315-970 São Paulo, SP, Brasil.
}

\section{Abstract}

The injector linac consists of a 100-keV electron gun, a beam conforming stage, and two acceleration structures. The beam focalization is made by solenoids, and correcting coils are provided for steering. In this work we describe the commissioning of the electron gun and the optical lattice of the beam conforming stage. The first beam images are shown.

\section{INTRODUCTION}

The Instituto de Física da Universidade de São Paulo (IFUSP) is building a two-stage $38 \mathrm{MeV}$ continuous wave racetrack microtron. Figure 1 shows an isometric view of the accelerator and the beam transport line [1], where it can be seen that the beam is generated and pre-accelerated in a linear accelerator.

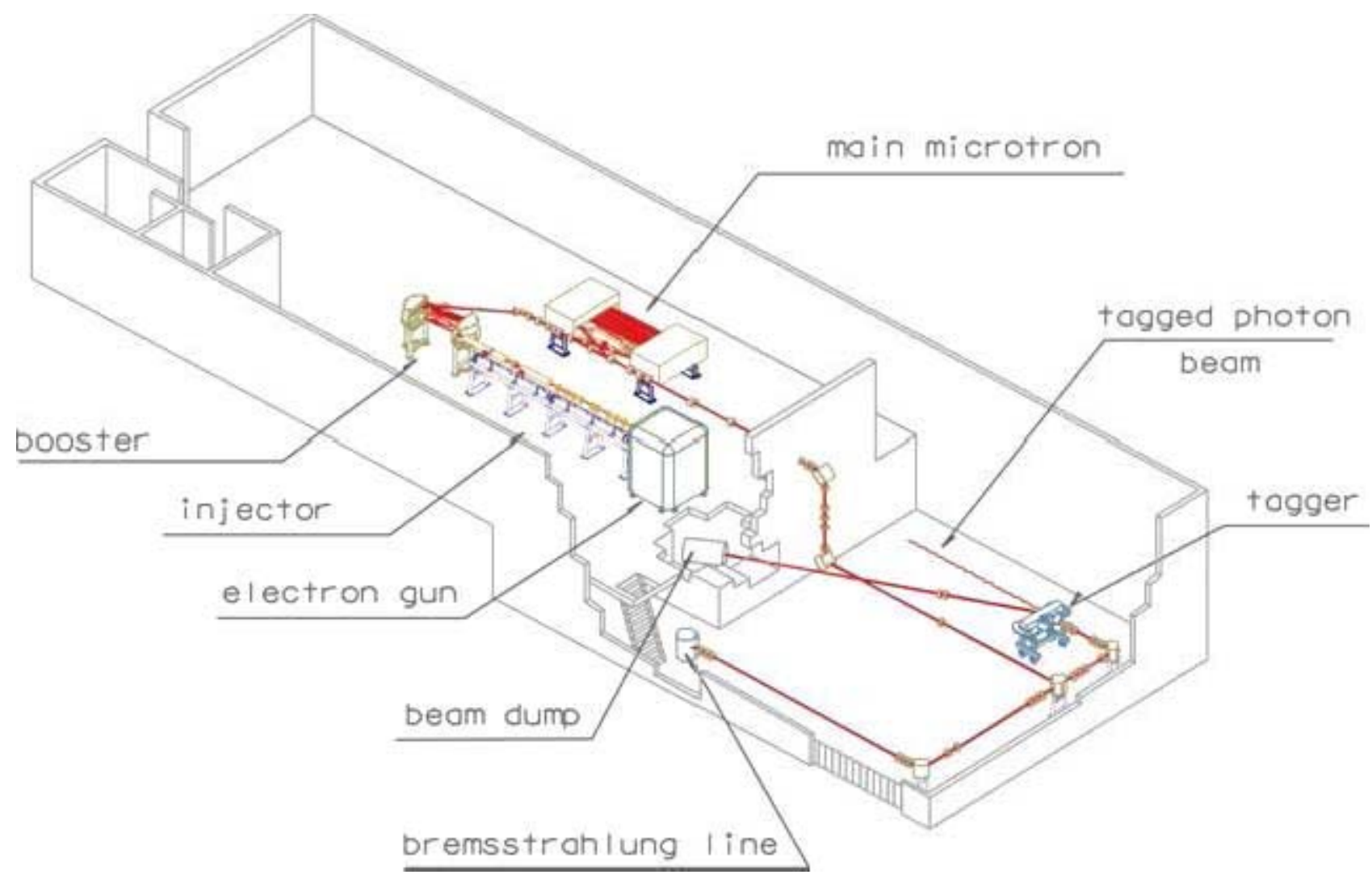

Figure 1: Isometric view of the accelerator in the accelerator building.

The injector linac consists of a beam conforming stage, with chopper and buncher systems, and two acceleration structures [2] (the first one with variable $\beta$, and the second one divided into two parts with different $\beta$ ). There is a 3$\mathrm{mm}$ diameter collimator at the entrance to the first acceleration structure.
The beam focalization is made by solenoids, and correcting coils are provided for steering. Figure 2 shows the injector stage in detail.

In this work we describe the commissioning of the 100 $\mathrm{keV}$ beam stage of the injector linac of the IFUSP microtron.

*tfsilva@if.usp.br 

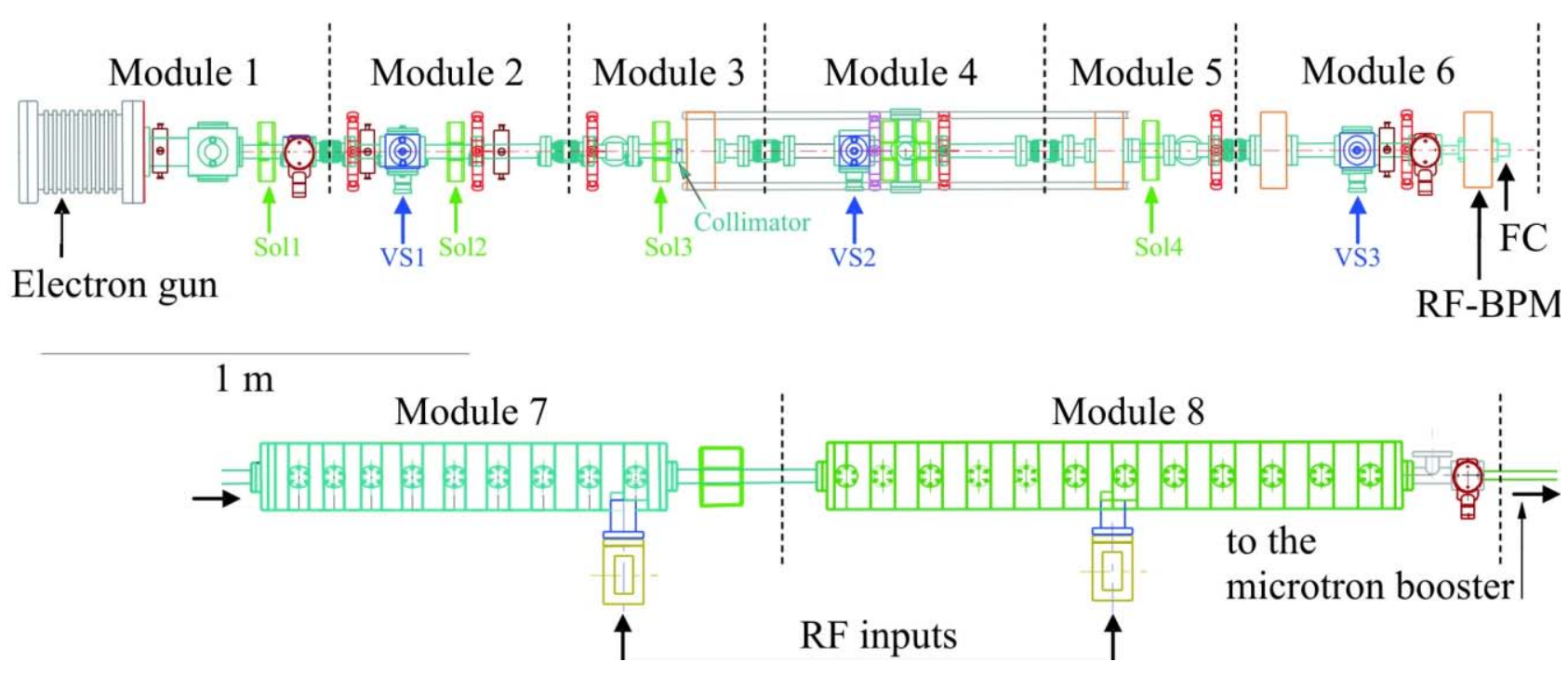

Figure 2: The injector system of the IFUSP microtron: FC stands for Faraday Cup, and RF-BPM for radio frequency beam position monitor.

\section{RESULTS}

The alignment tolerance for the injector system of the IFUSP microtron was statistically evaluated in a simulation procedure [3] as $0.23 \mathrm{~mm}$, for a beam loss at the first accelerator structure collimator limited to $10 \%$. A $0.18-\mathrm{mm}$ tolerance was achieved with our positioning devices [3].

After installation of the cathode (specifications presented in table 1), internal pressure in the $100 \mathrm{keV}$ beam stage stabilized between $1-2 \times 10^{-8}$ Torr [4], and we proceeded to energize the system. In a first step, the cathode was heated without $\mathrm{HV}$, in order to clean up the system. Then we increased the cathode-anode voltage (with the cathode off), in order to condition the HV. After the HV was successfully conditioned up to $110 \mathrm{kV}$, we proceeded to produce beam.

Table 1: Cathode specifications.

\begin{tabular}{ll}
\hline $\begin{array}{l}\text { Manufacturer } \\
\text { Model }\end{array}$ & Varian EIMAC Salt Lake \\
\hline Cathode type & Dispenser \\
Emission area & $0.1 \mathrm{~cm}^{2}$ \\
Emission & $3 \mathrm{~mA}-6.5 \mathrm{~V}$ \\
\hline
\end{tabular}

The beam tests were accomplished with a pulsed beam ( $1 \mu$ s pulses at $60 \mathrm{~Hz}$ ), since the cooling systems for the collimator and Faraday Cup were not operational. In this configuration, the maximum current was $10 \mathrm{nA}$, with the cathode filament at $6 \mathrm{~V}$ (below the recommended $6.5 \mathrm{~V}$ ), equivalent to a DC current of $0.15 \mathrm{~mA}$. Internal pressure with the beam on was kept between $4-6 \times 10^{-8}$ Torr.
Beam position and shape were monitored by three view-screens located at modules 1, 4 and 6 , as shown in figure 2. Beam images were acquired by closed circuit TV cameras at each view-screen position. An image digitazing system was designed and installed for data acquisition [5]. A beam spot image from VS1 can be seen in figure 3.

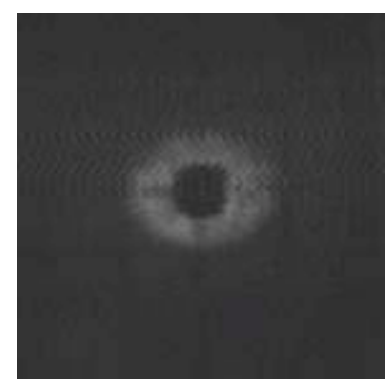

Figure 3: Beam spot image.

Figure 4 shows a beam intensity profile from VS2.

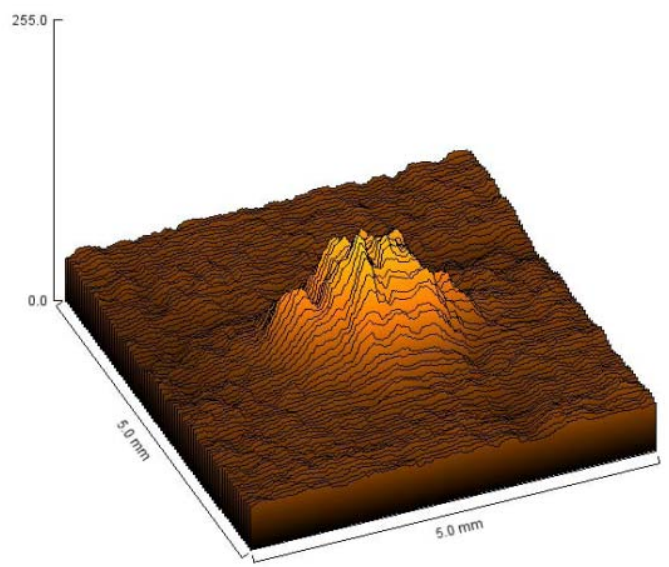

Figure 4: Beam intensity profile from VS2.

T02 Lepton Sources 
The beam spot observed at the 3 view-screens allowed for beam positioning, using the steerings, and focus optimization using the solenoids. The beam went through the whole section with the need of very small corrections with the steerings, attesting the good alignment procedure. After passing the beam through the whole conforming stage (modules 1-6), we proceeded to measure the beam emittance.

The emittance was measured as $(2.32 \pm 0.05)$ $\pi \cdot \mathrm{mm} \cdot \operatorname{mrad}[6]$.

\section{CONCLUSIONS}

We successfully commissioned the $100 \mathrm{keV}$ beam stage of the IFUSP Microtron injector linac. Beam characteristics are compatible with the required specifications for the linac operation.

Commissioning of the RF distribution and control systems is under way, and should be finished in a couple of months. Then we will be able to start the operation of the chopper and buncher systems and the accelerating structures up to the booster entrance.

\section{ACKNOWLEDGEMENTS}

This work was supported by Brazilian funding agencies FAPESP and CNPq.

\section{REFERENCES}

[1] RIOS, P. B., Linha de Transporte de Feixe do Microtron do IFUSP, M. Sc. Dissertation, USP, São Paulo, 2002.

[2] Takahashi, J., Projeto e construção de uma estrutura aceleradora de elétrons de onda contínua, PhD. Thesis, USP, São Paulo, 1996.

[3] T. F. Silva, P. B. Rios, M. N. Martins, Studies of the alignment tolerance for the injector system of the IFUSP microtron, in proceedings of European Particle Accelerator Conference, 2006, Edinburgh, UK.

[4] Vácuo

[5] SILVA, T. F., Início de operação e caracterização do sistema injetor do Mícrotron do IFUSP, M. Sc. Dissertation, USP, São Paulo, 2006.

[6] T. F. Silva, A. A. Malafronte, M. N. Martins, Emittance measurements at the $100 \mathrm{keV}$ beam stage of the injector linac of the IFUSP microtron, FRPMN010, PAC 2007. 